Araştırma Makalesi - Research Article

\title{
Süperkapasitör Uygulamaları için Elektrodepolanmış Kobalt Temelli Filmin Nikel Köpük Elektrot Üzerine Sentezi
}

\author{
Perihan Yılmaz Erdoğan ${ }^{1 *}$, Naime Özdemir ${ }^{2}$, Hüseyin Zengin ${ }^{3}$, Abdulcabbar Yavuz ${ }^{4}$ \\ Geliş / Received: 04/07/2019 \\ Revize / Revised: 26/12/2019 \\ Kabul / Accepted: 06/07/2020
}

\section{ÖZ}

$\mathrm{Bu}$ çalı̧̧ada, kobalt temelli film, süperkapasitör uygulamaları için nikel köpük akım toplayıcıları üzerine elektrodepolanmıştır. Kobalt temelli film, $-1,5$ V'luk sabit bir voltaj uygulanarak doğrudan pirofosfat elektrolitinden nikel köpük üzerine büyütüldü. Kobalt birikiminin döngüsel voltamogram ve kronoamperometrik verileri sunuldu. Elde edilen kobalt temelli modifiye nikel köpük elektrot daha sonra $\mathrm{KOH}$ elektrolitine aktarıldı. Kaplanmamış ve kaplanmış nikel köpük elektrotun elektrokimyasal davranışı bazik ortamda karakterize edildi. Kaplanmamış nikel köpük elektrotun elektro aktivitesi, kobalt film ile kaplandığında önemli ölçüde artığı gözlendi. Kobaltla modifiye edilmiş nikel köpük elektrotu $\mathrm{KOH}$ elektrolitinde yüksek çevrim kararlılığına sahipti. Kaplanmamış ve kaplanmış nikel köpük elektrotun morfolojisi SEM ile karakterize edildi. Elektrotun 5 ve $100 \mathrm{mV} \mathrm{s}^{-1}$ tarama hızlarındaki spesifik kapasitansı, sırasıyla $538 \mathrm{~F} \mathrm{~g}^{-1}$ ve $261 \mathrm{~F} \mathrm{~g}^{-1}$ olarak ölçüldü. Elde edilen kobalt temelli elektrotun hız sınırlayıcı adımı, yüzey kontrollü bir mekanizmaya sahip olduğu gözlendi.

Anahtar Kelimeler-Süperkapasitör, Elektrokimyasal Depolama, Katodik Potansiyel, Elektrolit

\footnotetext{
1*Sorumlu yazar iletișim: yilmazperihan8@gmail.com (http://orcid.org/0000-0002-1375-603X)

Kimya Bölümü, Fen-Edebiyat Fakültesi, Gaziantep Üniversitesi, Gaziantep, Türkiye

2İletişim: naimeozdemir027@gmail.com (http://orcid.org/0000-0003-4744-1316)

Kimya Bölümü, Fen-Edebiyat Fakültesi, Gaziantep Üniversitesi, Gaziantep, Türkiye

3̇letişim: hzengin@gantep.edu.tr (http://orcid.org/0000-0002-5540-725X)

Kimya Bölümü, Fen-Edebiyat Fakültesi, Gaziantep Üniversitesi, Gaziantep, Türkiye

4İletişim: ayavuz@gantep.edu.tr (http://orcid.org/0000-0002-7216-0586)

Metalurji ve Malzeme Mühendisliği, Mühendislik Fakültesi, Gaziantep Üniversitesi, Gaziantep, Türkiye
} 


\title{
Synthesis of Electrodeposition of Cobalt Based Film on a Nickel Foam Electrode for Supercapacitor Applications
}

\begin{abstract}
In this study, cobalt-based film was electrodeposited on nickel foam current collectors for supercapacitor applications. The cobalt-based film was grown directly from pyrophosphate electrolyte to nickel foam by applying a constant voltage of $-1.5 \mathrm{~V}$. Cyclic voltamogram and chroamperometric data of cobalt deposition were presented. The resulting cobalt based modified nickel foam electrode was then transferred into the $\mathrm{KOH}$ electrolyte. Electrochemical behavior of uncoated and coated nickel foam electrode was characterized in alkaline media. Electroactivity of bare nickel foam increased significantly when it was coated with cobalt film. Cobalt modified nickel foam electrode had high cycle stability in $\mathrm{KOH}$. The morphology of uncoated and coated nickel foam electrode was characterized by SEM. The specific capacitance of the electrode at the scan rates of 5 and $100 \mathrm{mV} \mathrm{s}^{-1}$ was measured as $538 \mathrm{~F} \mathrm{~g}^{-1}$ and $261 \mathrm{~F} \mathrm{~g}^{-1}$, respectively. The rate-limiting step of the obtained cobalt based electrode had a surface controlled mechanism.
\end{abstract}




\section{GİRIŞ}

Çevre kirliliği, iklim değişikliği ve küresel ısınma, fosil yakıtlara alternatif yeni enerji kaynaklarına ihtiyaç doğurmaktadır. [1]. Bu nedenle, sürdürülebilir ve yenilenebilir enerji kaynaklarından enerji elde edilmesi ve elde edilen bu enerjilerin istenilen zamanda kullanılması arzulanmaktadır. Elde edilen sürdürülebilir ve yenilenebilir enerjilerin kullanılması için depolanması gereklidir. Süperkapasitörler, enerji depolama sistemlerine yeni bir alternatif olarak son zamanlarda yaygın olarak çalışılmaktadır [2]. Elektrokimyasal süperkapasitörler, yüksek enerji yoğunluğu, uzun çevrim ömrü ve yüksek güç yoğunluğu nedeniyle dikkat çekmektedir. Süperkapasitörler, genel olarak pillerden daha yüksek güç yoğunluğuna ve dielektrik kapasitörlerden daha yüksek enerji yoğunluğuna sahiptirler [3]. Ultrakapasitörler olarak da bilinen süperkapasitörler hızlı depolama ve enerji salınımına sahip ideal bir elektrokimyasal enerji depolama sistemi (pseudo kapasitörler) ya da Elektriksel Çift Katmanlı Kapasitörlerdir. Süperkapasitörler; sürekli güç kaynakları, hibrit elektrikli araçlar ve hücresel cihazların hafiza koruması gibi çeşitli uygulamalar için kullanılabilir [4]. Elektriksel iletkenlik, yüzey kimyası, aktif elektrot malzemelerinin gözenek büyüklüğü ve yüzey alanı, süperkapasitörlerin performansını belirlemede önemli rol oynar [5].

Süperkapasitörler genel olarak yüksek yüzey alanına sahip elektrotlar kullanıldığında yüksek kapasitansa sahiptirler. Süperkapasitörlerde üç tip elektrot malzemesi kullanılır. Karbon temelli malzemeler (karbon nanotüpler, aktif karbon ve grafen gibi) [6], iletken polimerler [7] ve geçiş metali oksitleri/hidroksitleri [8]. Süperkapasitörlerde kullanılan elektrot malzemelerinin özellikleri, elektrolitin performansını ve uygulanan potansiyel kapasitansın belirlenmesinde oldukça önemlidir. Metal oksitler, süperkapasitörlerdeki yüksek performansları nedeniyle son yıllarda büyük ilgi görmüştür [9]. Yüksek performanslı süperkapasitörler elde etmek için metal oksit ve kompozitleri elektrot malzemesi olarak yaygın şekilde kullanılmaktadır [10]. Kalay oksit [11], kobalt oksit [12], çinko oksit [13] ve diğer geçiş metal oksitler süperkapasitör için elektrot malzemeleri olarak kullanılabilir. Süperkapasitörlerde kullanılan bu metal oksitler arasında, $\mathrm{CoOx}$, psödokapasitif davranışı nedeniyle ümit verici elektrot malzemeleri olarak kullanılmıştır [14].

Kobalt oksitler/hidroksitler; döngüsel kararlılık, yüksek iletkenlik ve yüksek kapasitansları nedeniyle süperkapasitörlerde tercih edilirler [15]. $\mathrm{Co}_{3} \mathrm{O}_{4}$ 'ün uzun süreli döngüsel performansı, geniş yüzey alanı, yüksek iletkenliği ve yüksek korozyon direnci gösterdiği görülmektedir. Bu nedenle, superkapasitörler için alternatif bir elektrot malzemesi olarak kabul edilmiştir [15]. $\mathrm{Co}(\mathrm{OH})_{2}$-bazlı malzemeler katmanlı yapılara sahiptir ve bu yapılar yüksek yüzey alanına sebep olur. Dolayısıyla iyonların elektrot yüzeyine taşınması ve elektrot yüzeyinden ayrılması hızlıdır [16]. Kobalt temelli malzemeler rutenyum temelli malzemelere göre çok daha ekonomik olması sebebiyle süperkapasitör uygulamalarında yaygın olarak çalışılmaktadır [17].

Elektrot malzemesi, süperkapasitörlerin genel elektrokimyasal performansını düzenlemede en önemli bileşenlerden biri olduğundan ve elektrodun yüzey alanının büyüklüğü kapasitansı önemli derecede etkilediğinden, bu çalışmada elektrot olarak daha yüksek yüzey alanına sahip nikel köpük kullanılmıştır [16]. Nikel köpük elektrotun elektrokimyasal özellikleri (spesifik kapasitans, güç yoğunluğu ve enerji yoğunluğu) arttırılabilir. Bunun için iletken polimerler veya metaller/alaşımlar nikel köpük üzerine kaplanabilir. Bu çalışmanın temel amacı, bir nikel köpük elektrotu üzerine kararlı ve elektrokimyasal olarak aktif bir kobalt temelli kaplamayı elektrokimyasal olarak pirofosfat ortamından elde etmektir ve elde edilen bu elektrodun süperkapasitör uygulamasında kullanılmasını araştırmaktır. Kobalt, nikel köpük üzerine pirofosfat çözeltisi içinde sabit voltaj uygulanarak elde edildi. İndirgenecek metalin standart elektrot potansiyeline göre, metalin katot üzerinde birikmesi için hücreye belirli bir voltaj değeri uygulandı.

\section{MALZEME VE METOT}

\section{A. Malzemeler}

Potasyum pirofosfat $\left(\mathrm{K}_{4} \mathrm{P}_{2} \mathrm{O}_{7}\right.$, Sigma Aldrich, \%98), potasyum hidroksit ( $\mathrm{KOH}$, Merck, \%90) monopotasyum fosfat $\left(\mathrm{KH}_{2} \mathrm{PO}_{4}\right.$, Sigma Aldrich, \%99) ve kobalt (II) klorür heksahidrat $\left(\mathrm{CoCl}_{2} \cdot 6 \mathrm{H}_{2} \mathrm{O}, \mathrm{Merck}\right.$, \%98) kimyasalları saflaştırılmadan doğrudan kullanıldı. 


\section{B. CoOx Filmin Elektrokimyasal Olarak Depolanması}

Nikel köpük elektrodu üzerine kobalt temelli filmin depolanması elektrokimyasal yöntem ile gerçekleştirildi. Kobalt pirofosfat çözeltisi (50 $\mathrm{mM} \mathrm{CoCl}_{2}, 0,7 \mathrm{M} \mathrm{K}_{4} \mathrm{P}_{2} \mathrm{O}_{7}$ ve $0,07 \mathrm{M} \mathrm{KH}_{2} \mathrm{PO}_{4}$ ) saflaştırılmış su kullanılarak hazırlanmıştır. Kobaltın elektrokimyasal olarak elde edilmesinde karşıt elektrot olarak titanyum kaplı platin, çalışma elektrodu olarak nikel köpük elektrot ve referans elektrot olarak $\mathrm{Ag} / \mathrm{AgCl}$ içeren üç elektrotlu bir sistem kullanılarak gerçekleştirildi. Nikel köpük çalışma elektrodu ve karşıt elektrot biriktirme işlemi sırasında paralel olarak yerleştirildi. Kobalt, 200 saniye boyunca -1,5 V uygulanarak potansiyostatik olarak depolandı. Kobalt film nikel köpük üzerine biriktirildikten sonra, elektrot saf suyla yıkandı ve kurutuldu. Tüm deneyler oda sıcaklığında $\left(20 \pm 2^{\circ} \mathrm{C}\right)$ gerçekleştirildi.

\section{Elektrodun Karakterizasyonu}

Kaplanmamış nikel köpük ve CoOx kaplanmış nikel köpüklerin yüzey morfolojisi, taramalı elektron mikroskobu (Zeiss Gemini SEM 300 FEGSEM, Carl Zeiss, Oberkochen, Almanya) ile incelendi. Tüm elektrokimyasal ölçümler, üç elektrotlu bir potansiyostat sistemi (Princeton Applied Research, VersaSTAT 3 AMETEK, Oak Ridge, TN, ABD) kullanılarak yapıldı. Üç elektrotlu elektrokimyasal ölçümler için kobalt kaplı nikel köpügü doğrudan çalışma elektrodu, titanyum kaplı platin karşıt elektrot ve $\mathrm{Ag} / \mathrm{AgCl}$ referans elektrodu olarak kullanıldı. Elektrolit olarak sulu $1 \mathrm{M} \mathrm{KOH}$ çözeltisi kullanıldı. Kobalt nikel köpük elektrodu üzerine katodik olarak elektrokimyasal yöntem ile depolandı. Bu filmler elektrokimyasal karakterizasyon için $1 \mathrm{M} \mathrm{KOH}$ içinde $-0,4 \mathrm{~V}$ ila $+0,4 \mathrm{~V}$ arasında tarandı. Elektrot dönüşümlü voltametride $-0,4 \mathrm{~V}$ ile $+0,4 \mathrm{~V}$ arasında farklı tarama hizlarında $\left(5,10,20,50\right.$ ve $\left.100 \mathrm{mV} \mathrm{s}^{-1}\right)$ tarandi.

\section{BULGULAR VE TARTIŞMA}

\section{A. CoOx Filmin Nikel Köpük Yüzey Üzerine Sentezi}

Kobalt film, pirofosfat ortaminda $\left(0,07 \mathrm{M} \mathrm{KH}_{2} \mathrm{PO}_{4}\right.$ and $\left.0,7 \mathrm{M} \mathrm{K}_{4} \mathrm{P}_{2} \mathrm{O}_{7}\right) 200$ saniye boyunca $-1,5 \mathrm{~V}$ potansiyel uygulanarak bir nikel köpük elektrodu üzerine potansiyostatik olarak depolandı. Şekil 1 a, $25{ }^{\circ} \mathrm{C}$ 'de pirofosfat çözeltisindeki kobaltın nikel köpük elektrotu üzerine depolanmasının dönüşümlü voltametri eğrisini göstermektedir. Kobaltın nikel köpük elektrodu üzerine depolanması, yaklaşık -1,3 V'da başlar; bu, daha fazla negatif voltaj uygulandığında kobalt birikmesine neden olabilir [17]. Şekil 1 b, 200 saniye boyunca $-1,5 \mathrm{~V}$ uygulanarak elde edilen kobalt temelli filmin birikmesi için kronoamperometrik verileri göstermektedir. Şekil 1 b’nin grafiğindeki dalgalanmalar kobalt biriktirme sırasında nikel köpük elektrotunda hidrojen gazı çıkışının sonucudur. Kobaltın elektrokimyasal olarak depolanması hidrojenin ortaya çıkması ile oluşur [18].
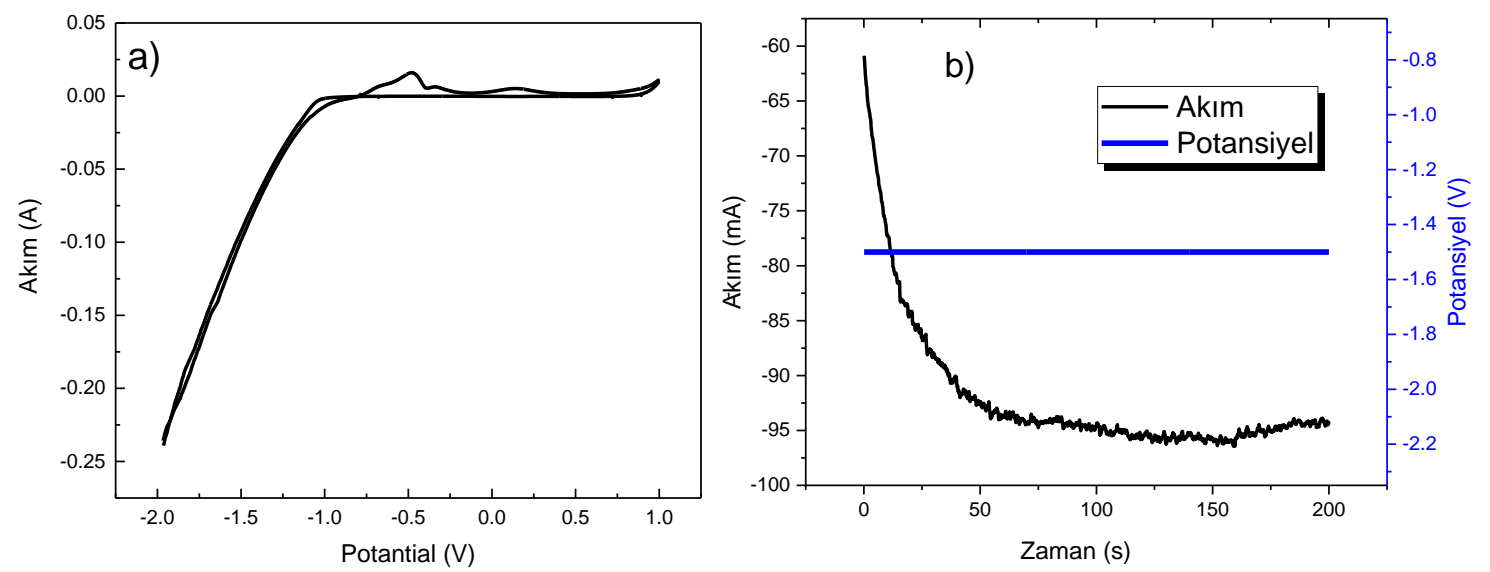

Şekil 1. a) $50 \mathrm{mM} \mathrm{CoCl}_{2}$ içeren pirofosfat çözeltisi içerisindeki nikel köpük elektrodunun, $\mathrm{Ag} / \mathrm{AgCl}$ referans elektroduna karş1 $50 \mathrm{mV} \mathrm{s}{ }^{-1}$ tarama hızında dönüşümlü voltamogram eğrisi. b) Pirofosfat ortamında bulunan nikel köpük elektrot üzerine -1,5 V uygulanarak elde edilen kobalt filmin kronoamperometrik eğrisi. 


\begin{tabular}{|c|c|c|}
\hline & $\begin{array}{l}\text { BŞEÜ Fen Bilimleri Dergisi } \\
7(2), 638-648,2020\end{array}$ & $\begin{array}{r}\text { BSEU Journal of Science } \\
\text { DOI: } 10.35193 / \text { bseufbd } .586983\end{array}$ \\
\hline $\begin{array}{l}\text { BiLECCKS SEYH EDEBALI } \\
\text { UNIVERSITESI }\end{array}$ & & 58-7575 (http://dergipark.gov.tr/bseufbd) \\
\hline
\end{tabular}

Şekil 2. a kaplanmamış nikel köpük elektrotunun yüzey görüntüsünü göstermektedir. Şekil 2. b 200 saniye boyunca -1,5 V potansiyel uygulanarak elde edilen kobalt depolanmış nikel köpük yüzeyinin görüntüsünü göstermektedir. Şekil 2. c potansiyel uygulanarak elde edilen kobalt depolanan nikel köpük elektrotunun $1 \mathrm{M}$ $\mathrm{KOH}$ elektrolitinden çıkarıldıktan sonraki yüzey görüntüsünü göstermektedir. Kaplanmamış ve kobalt kaplanmış nikel köpük elektrotların SEM görüntüleri de Şekil 2'de verilmiştir.

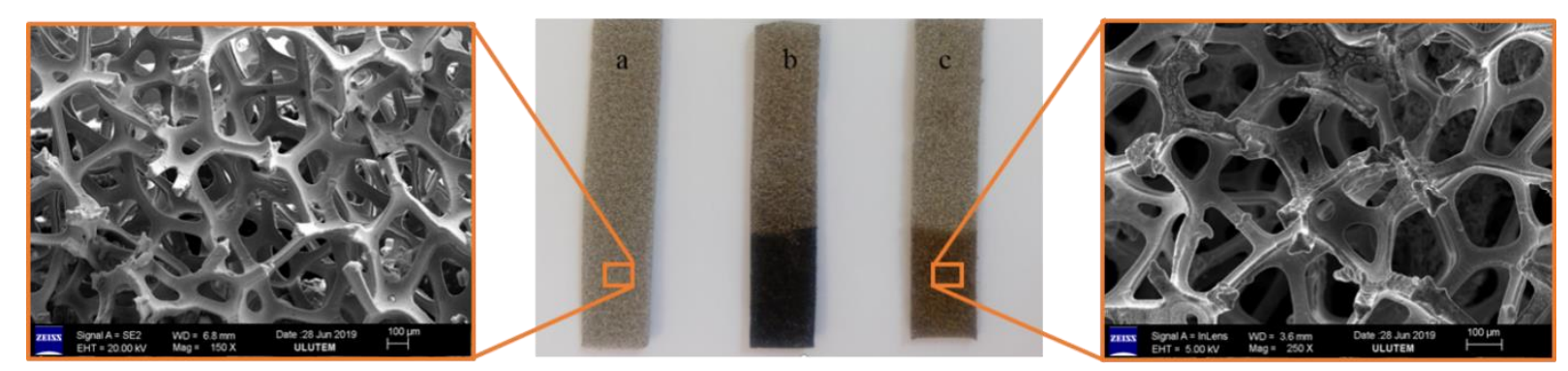

Şekil 2. a) Nikel köpük elektrot b) -1,5 V potansiyel uygulanarak elde edilen kobalt temelli nikel köpük elektrot c) elde edilen kobalt filmin, $1 \mathrm{M} \mathrm{KOH}$ elektroliti içerisindeki formunu göstermektedir.

\section{B. Elektrotun Karakterizasyonu}

Pirofosfat ortamında elde edilen kobalt temelli kaplanmış nikel köpük elektrot, filmin elektrokimyasal performansını belirlemek için $\mathrm{KOH}$ elektroliti içerisine aktarıldı. Şekil 3 kobalt temelli filmin $1 \mathrm{M} \mathrm{KOH}$ içinde $0,4 \mathrm{~V}$ ve $+0,4 \mathrm{~V}$ arasında $50 \mathrm{mV} \mathrm{s}^{-1}$ tarama hızında dönüşümlü voltamogram eğrilerini göstermektedir. Kobalt temelli film, dönüşümlü voltametri tekniği ile analiz edildiğinde yaklaşık 15 taramadan sonra kararlı olduğu görüldü (Şekil 3 a). Kobalt temelli nikel köpük elektrodunun çevrimi, kısa sürede (birkaç döngüde) gerçekleşti, çünkü hem dönüşümlü voltametride hem de kobalt film elde edilirken kullanılan elektrolitler, sulu çözeltiler içermektedir. Sulu elektrolitler, iyonik sıvı elektrolitlere kıyasla daha kısa döngü kararlılığına sahiptir [19]. Sulu elektrolitler, $\left(\mathrm{H}_{2} \mathrm{SO}_{4}, \mathrm{KOH}, \mathrm{Na}_{2} \mathrm{SO}_{4}\right.$ vb. gibi) organik elektrolitlere kıyasla düşük maliyetli, yüksek iyonik iletkenlik, toksik olmayan ve kullanım kolaylığı gibi avantajlara sahiptir. Şekil 3 b, 15 döngüden sonra kararlı olan kobalt kaplanmış nikel köpük elektrodunun (kırmızı çizgi) ve kaplanmamış nikel köpük elektrodunun (siyah çizgi) $1 \mathrm{M} \mathrm{KOH}$ içindeki dönüşümlü voltametre sonuçlarını göstermektedir. Kobalt film, elektrokimyasal olarak aktiftir ve $\mathrm{KOH}$ elektrolitinde $-0,4 \mathrm{~V}$ ile $+0,4 \mathrm{~V}$ arasında kararlıdır. Kaplanmış elektrot 0 ile 0,4 arasında da taranabilir fakat redoks tepe noktalarının daha geniş olarak görülmesi için $-0,4$ ile $0,4 \mathrm{~V}$ arasında taranmıştır. Şekil 3 b incelendiğinde, mevcut elektrot olarak kullanılan kaplanmamış nikel köpük elektrodun (siyah çizgi) 1 M KOH elektrolitinde güçlü yükseltgenme ve indirgeme tepelerine sahip olmadığı gözlendi. Aksine, kobalt depolanmış nikel köpük elektrot, (kırmızı çizgi) belirgin yükseltgenme ve indirgenme tepe noktalarına sahiptir. Nikel köpük elektrodun (siyah çizgi, Şekil 3 b) dönüşümlü voltametredeki akım miktarı, kobalt temelli nikel köpük elektrot akım miktarıyla kıyaslandığında oldukça az olduğu bulundu. Şekil 3 a ve b, kobaltın $+0,1$ V'da yükseltgenme tepe noktasının ve $0,22 \mathrm{~V}$ ile $0,18 \mathrm{~V}$ 'da indirgenme tepe noktalarının olduğunu göstermektedir. 

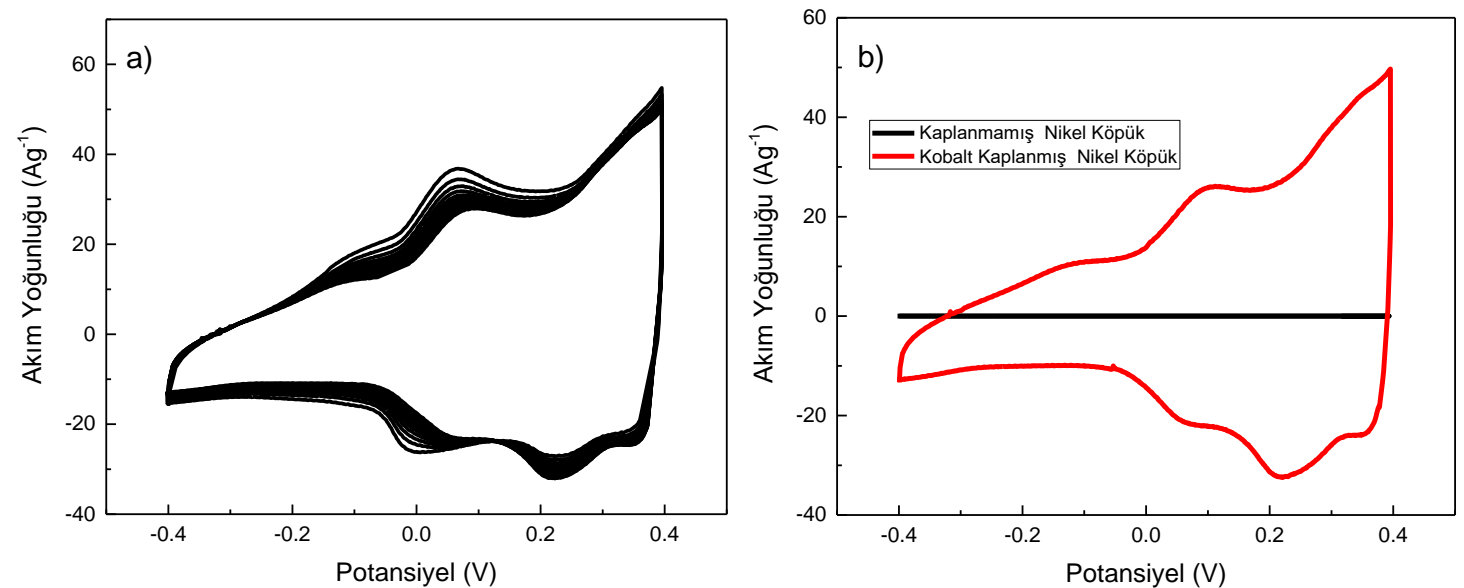

Sekil 3. a) Kobalt depolanmıs nikel köpük elektrodunun $50 \mathrm{mV} \mathrm{s}^{-1}$ tarama hızındaki $1 \mathrm{M} \mathrm{KOH}$ elektrolitindeki dönüșümlü voltametri eğrisi b) Nikel köpük elektrodunun (siyah çizgi) ve kobalt kaplanmış nikel köpük elektrodunun (kırmızı çizgi) KOH elektroliti içerisindeki dönüşümlü voltametri eğrisi $\left(v=50 \mathrm{mV} \mathrm{s}^{-1}\right)$.

Şekil 4 farklı tarama hızlarında $\left(5,10,20,50\right.$ ve $\left.100 \mathrm{mV} \mathrm{s}^{-1}\right) 1 \mathrm{M} \mathrm{KOH}$ elektroliti içerisinde kobalt temelli filmin, dönüşümlü voltametri eğrilerini göstermektedir. Eğriler yükseltgenme ve indirgenme tepe noktalarına sahiptirler. Elektriksel Çift Katmanlı Süperkapasitörlere potansiyel uygulandığında iyonlar yüzeye yapışırken, pseudo süperkapasitörlerde faradaik reaksiyonlar (redoks reaksiyonları) gerçekleşir [20]. Faradaik reaksiyon oluşturan malzemeler, iletken polimerler ve metal oksit/hidroksitlerdir. Metal temelli pseudo kapasitör elektrotlarına örnek olarak $\mathrm{V}_{2} \mathrm{O}_{5}$ [21], $\mathrm{Ni}(\mathrm{OH})_{2}$ [22], $\mathrm{MnO}_{2}$ [23] ve $\mathrm{CoOOH}$ bazlı malzemeler verilebilir. Elektriksel Çift Katmanlı Süperkapasitör elektrotlarının dönüşümlü voltametri grafiğgi dikdörtgen şeklindeyken, metal oksitlerin grafiği tepe noktalarına sahip olabilirler. Şekil 4 'te sunulan veriler yükseltgenmiş formun $+0,4$ $V^{\prime}$ da ve indirgenmiş formun $-0,4 V^{\prime}$ da gerçekleştiğini göstermektedir. Akım yoğunluğu, artan tarama hızı ile artmaktadır. Kobalt temelli filmin çeşitli formlarının varlı̆̆ı, redoks reaksiyonlarının potansiyel piklerinin değişmesine katkıda bulunur ve bu literatürle genel olarak uyumludur [24].

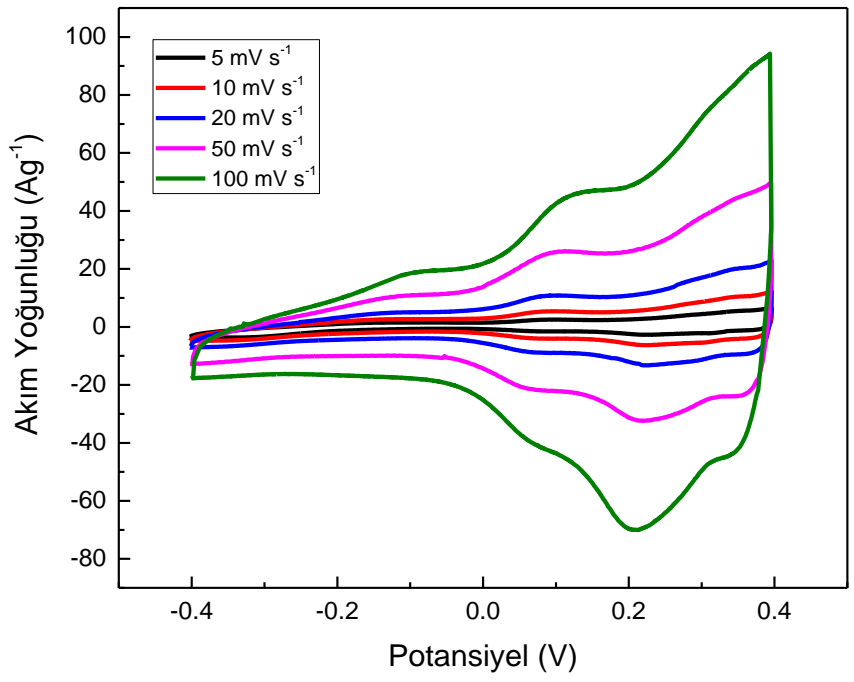

Şekil 4. $-1,5 \mathrm{~V}$ uygulayarak elde edilen kobalt temelli nikel köpük elektrodun $1 \mathrm{M} \mathrm{KOH}$ elektroliti içerisinde 5, 10, 20,50 ve $100 \mathrm{mV} \mathrm{s}^{-1}$ tarama hızlarındaki dönüşümlü voltametri eğrileri. 


\begin{tabular}{|c|c|c|}
\hline & $\begin{array}{l}\text { BŞEÜ Fen Bilimleri Dergisi } \\
7(2), 638-648,2020\end{array}$ & $\begin{array}{r}\text { BSEU Journal of Science } \\
\text { DOI: } 10.35193 / \text { bseufbd. } 586983\end{array}$ \\
\hline & & 58-7575 (http://dergipark.gov.tr/bseufbd) \\
\hline
\end{tabular}

Çeşitli tarama oranlarında yüksek kapasitans tutma, enerji depolama malzemelerinin yüksek güç yoğunluklarının karşılamasında önemli bir özelliktir. Şekil 5 farklı tarama hızlarında $\left(5,10,20,50\right.$ ve $100 \mathrm{mV} \mathrm{s}^{-}$ $\left.{ }^{1}\right)$ kobalt temelli nikel köpük elektrodunun spesifik kapasitansını göstermektedir. Şekil 5’te görüldüğü gibi kobalt temelli nikel köpük elektrodun kapasitansı tarama hızı ile ters orantılıdır. Tarama hızını azaltmak, elektrolitin filme nüfuz etme süresini arttırır ve böylece elektrot malzemesinin iç yüzeyi ile daha fazla temasta olur. $\mathrm{Bu}$ nedenle, elektrot-elektrolit ara yüzünde daha fazla iyon/elektron reaksiyona girebilir ve daha uzun zamanda daha yüksek kapasitansa neden olabilir. $5 \mathrm{mV} \mathrm{s}^{-1}$ 'lik bir tarama hızında, gözlenen kapasitans, elektrolit ve elektrotun uzun süre birbiriyle temas ettiğinden $538 \mathrm{~F} \mathrm{~g}^{-1}$ 'dir çünkü elektrotun yüzeyinde iyonlar daha fazla taşınabilir. 100 $\mathrm{mV} \mathrm{s}^{-1}$ tarama hızında ise daha kısa süreli çözelti teması nedeniyle spesifik kapasitans $207 \mathrm{~F} \mathrm{~g}^{-1}$ 'a düşmektedir. $\mathrm{Bu}$ çalışma kapsamında elde edilen kobalt temelli elektrodun süperkapasitör uygulamalarındaki performansı literatürdeki diğer kobalt temelli elektrotların performansıyla kıyaslanması Tablo 1'de verilmiştir.

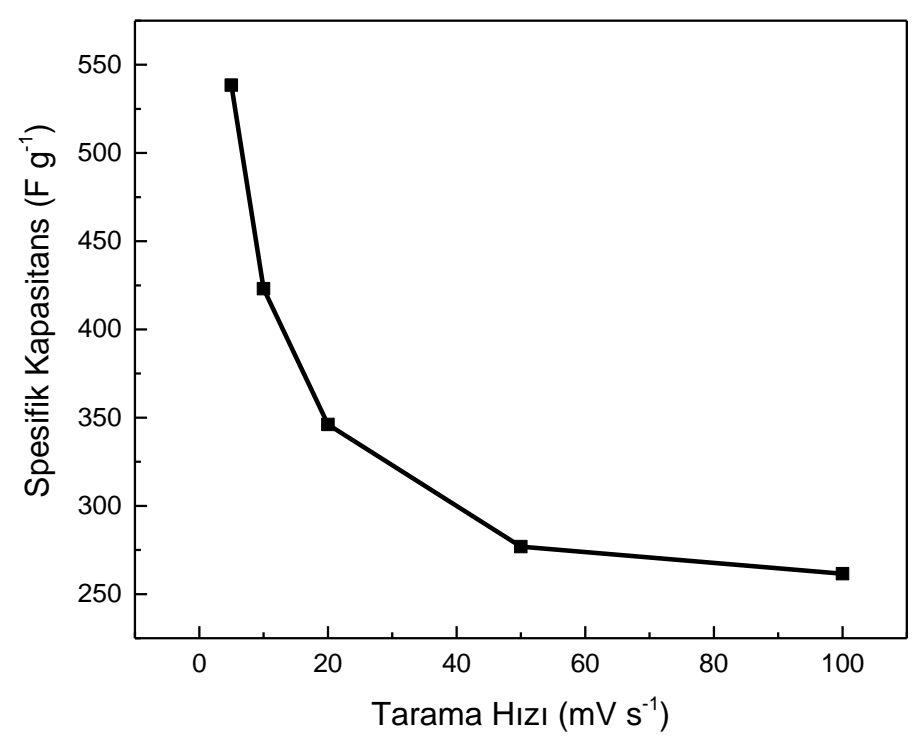

Şekil 5. Kobalt temelli nikel köpük elektrodun spesifik kapasitansının tarama hızına bağlı değişimi.

Cottrell denklemi, elektronun reaksiyon mekanizmasını veya elektrolit ve elektrot yüzeyi arasındaki iyon transferini anlamada kullanılabilir. Kobalt temelli nikel köpük elektrotunun $1 \mathrm{M} \mathrm{KOH}$ içindeki hız sınırlayıcı reaksiyonunu incelemek için bir $\log (v)$ ve $\log \left(i_{p}\right)$ grafiği çizildi. Şekil 6'te kullanılan $v$, tarama hızını sembolize ederken $i_{p}$ yükseltgenme ve indirgenme tepe noktalarının akım değerlerini göstermektedir. $\mathrm{Bu}$ değerler Şekil 4'te gösterilen maksimum tepe noktalarından alınmıştır. $\log (v)$ veya $\log \left(i_{p}\right)$ eğimi 0,5 'ten düşük olduğunda reaksiyon kinetik olarak sınırlanır. Eğim 0,5 olduğunda, reaksiyon tamamen difüzyon sınırlıdır. Eğim 1'e eşit ise, reaksiyon mekanizması tamamen yüzey reaksiyonu sınırlıdır [25]. Yükseltgenme ve indirgenme tepeleri için hesaplanan $\log (v), \log \left(i_{p}\right)$ eğimi, sırasıyla 0.98 ve 1.04 'dir. Böylece, kobalt kaplanmış nikel köpük ile $\mathrm{KOH}$ elektroliti arasında gerçekleşen redoks reaksiyonu genel itibariyle yüzey sınırlı bir mekanizmaya sahiptir. 


\begin{tabular}{|c|c|c|}
\hline & $\begin{array}{l}\text { BŞEÜ Fen Bilimleri Dergisi } \\
7(2), 638-648,2020\end{array}$ & $\begin{array}{r}\text { BSEU Journal of Science } \\
\text { DOI: } 10.35193 / \text { bseufbd } .586983\end{array}$ \\
\hline $\begin{array}{l}\text { BiLECCKS SEYH EDEBALI } \\
\text { UNIVERSITESI }\end{array}$ & & 58-7575 (http://dergipark.gov.tr/bseufbd) \\
\hline
\end{tabular}

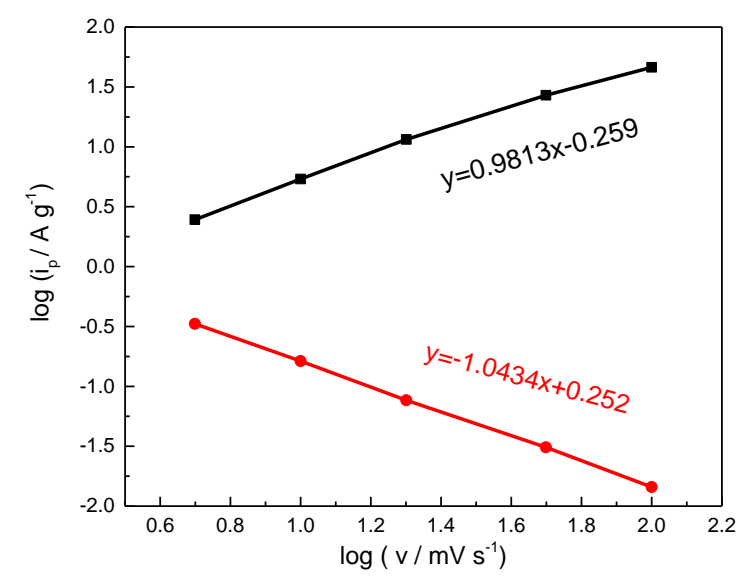

Şekil 6. Farklı tarama hızlarının logaritmasının maksimum yükseltgenme ve indirgenme tepe noktalarının logaritmasına karşı grafiği. Tepe noktalarının değerleri Şekil 4'ten alınmıştır.

Kaplanmamış nikel köpük elektrotun (Şekil 7 a ve 7 b) ve CoOx depolanmış nikel köpük elektrotunun (Şekil 7 c ve 7 d) yüzey morfolojileri, taramalı elektron mikroskobu (SEM) ile yapılmıştır. Filmlerin morfolojik görüntüleri iki farklı çözünürlükte elde edildi (15000X ve 100000X büyütme). Şekil 7 a ve b'de kaplanmamış nikel köpük elektrotunun büyütülmüş SEM görüntüsü yüzeyin temiz ve pürüzsüz olduğunu göstermektedir. Nikel köpük üzerine $-1,5 \mathrm{~V}$ uygulanarak elde edilen $\mathrm{CoOx}$ filmin yüzey görüntüsü Şekil 7 c ve d'de verilmektedir. Biriktirme işleminden sonra, CoOx filmin nikel köpük yüzeyine düzgün bir şekilde dağıldı $\breve{g}_{1}$ görülebilir. Bu morfolojinin varlığı, kobalt temelli kaplamanın topaklanmış parçacıklardan oluştuğunu ve nikel köpük yüzeyine biriktiğini gösterir.
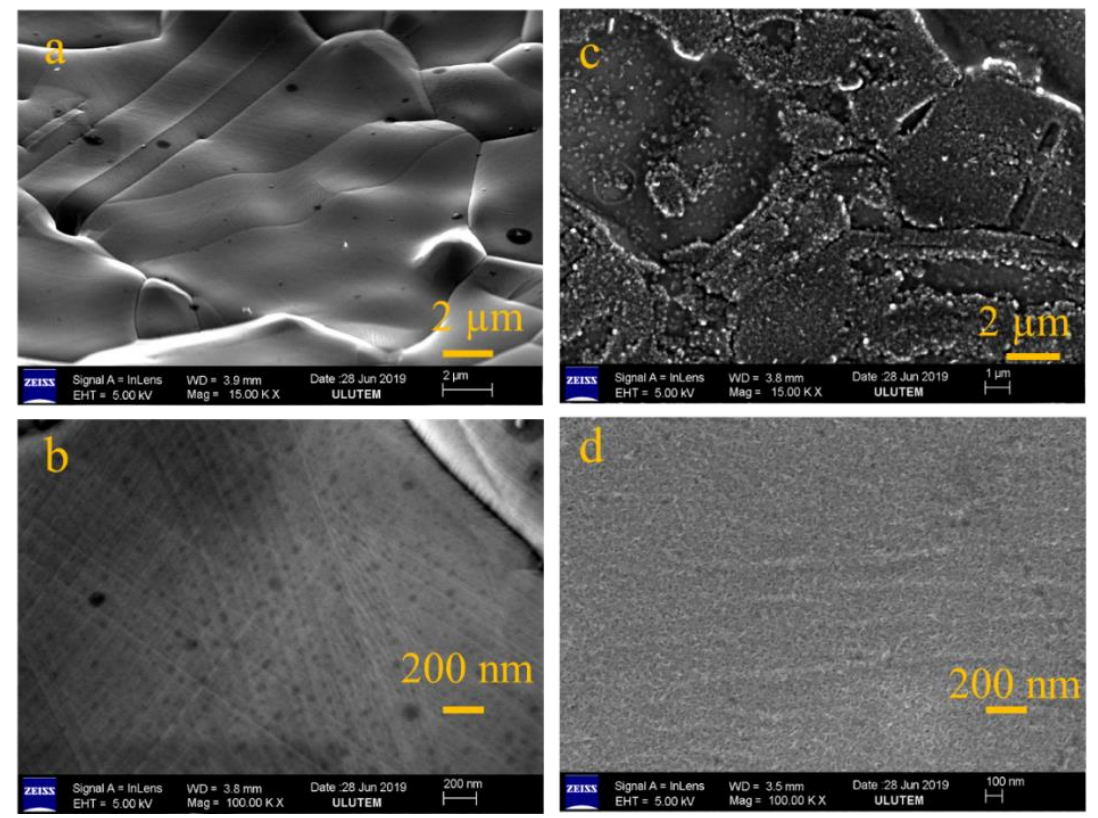

Şekil 7. (a) ve (b) kaplanmamış nikel köpük elektrotunun; (c) ve (d) kobalt kaplanmış nikel köpük elektrotunun SEM görüntüleri. 
Tablo 1. Süperkapasitör uygulamalarında kullanılan kobalt temelli elektrotların performansları.

\begin{tabular}{|c|c|c|c|c|}
\hline Elektrot & Elde Etme Metodu & Kapasitans & Döngü Kararlılığı & Referans \\
\hline $\begin{array}{l}\text { Nikel köpük elektrot } \\
\text { üzerinde } \mathrm{CoOx}\end{array}$ & Eletrokimyasal depolama & $\begin{array}{l}538 \mathrm{~F} \mathrm{~g}^{-1}, 5 \\
\mathrm{mV} \mathrm{s}^{-1}\end{array}$ & 1000 döngüden sonra \% 89 & Bu çalışma \\
\hline $\mathrm{CoOOH}+\mathrm{CNT}$ & $\begin{array}{l}\text { İki adımlı hidrotermal ve } \\
\text { yükseltgenme methodu }\end{array}$ & $\begin{array}{l}270 \mathrm{~F} \mathrm{~g}^{-1}, 5 \\
\mathrm{mV} \mathrm{s}^{-1}\end{array}$ & 10000 döngüden sonra \% 79 & {$[26]$} \\
\hline $\mathrm{CoOOH}$ on $\mathrm{Ni}$ foam & Hidrotermal sentez & $198 \mathrm{~F} \mathrm{~g}^{-1}$ & 5000 döngüden sonra \% 83 & {$[27]$} \\
\hline $\mathrm{Co}_{2} \mathrm{O}_{3}$ on $\mathrm{NiO}$ & Elektrodepolama & $\begin{array}{l}345 \mathrm{~F} \mathrm{~g}^{-1} \\
20 \mathrm{mV} \mathrm{s}^{-1}\end{array}$ & 200 döngüden sonra $>\% 50$ & {$[28]$} \\
\hline $\begin{array}{l}\text { Bakır üzerine } \mathrm{Co}+ \\
\mathrm{Co}(\mathrm{OH})_{2}\end{array}$ & Elektrodepolama & $\begin{array}{l}549 \mathrm{~F} \mathrm{~g}^{-1}, 5 \\
\mathrm{mV} \mathrm{s}^{-1}\end{array}$ & 450 döngüden sonra $\% 84$ & [29] \\
\hline $\begin{array}{l}\text { Grafit üzerine } \\
\mathrm{CoOOH}+\mathrm{Co}(\mathrm{OH})_{2}\end{array}$ & $\begin{array}{l}\text { Electrodepolama ve baz } \\
\text { ortamında oksitleme }\end{array}$ & $\begin{array}{l}886 \mathrm{~F} \mathrm{~g} \mathrm{~g}^{-1}, 5 \\
\mathrm{mV} \mathrm{s}^{-1}\end{array}$ & $90.1 \%$ after 1000 cycles & {$[30]$} \\
\hline
\end{tabular}

\section{SONUÇLAR}

Süperkapasitörlerin performansını belirlemede en önemli faktörlerden biri kullanılan elektrot malzemelerin yüksek yüzey alanına sahip olmasıdır. Bu çalışmada, pirofosfat ortamındaki kobalt, 200 saniye boyunca nikel köpük elektroduna $-1,5 \mathrm{~V}$ uygulanarak potansiyostatik olarak depolandı. Daha sonra kobalt depolanmış nikel köpük elektrodu, $1 \mathrm{M} \mathrm{KOH}$ elektrolitine aktarıldı. Kobalt temelli film, $1 \mathrm{M} \mathrm{KOH}$ içerisinde $+0,4$ V'da yükseltgendi ve -0,4 V'da indirgendi. Elde edilen film SEM ile karakterize edildi. Kobalt depolanmış nikel köpük elektrot $5 \mathrm{mV} \mathrm{s}^{-1}$ tarama hızında $538 \mathrm{~F} \mathrm{~g}^{-1}$ spesifik kapasitansa sahiptir. Kobalt temelli elektrot ve $\mathrm{KOH}$ elektroliti arasındaki reaksiyon genel olarak yüzey kontrollü mekanizmadan oluşmaktadır. Gözenekli nikel köpük yüzeyindeki kobalt temelli elektrot kolayca üretilebilir. Nikel köpük altlığın elektrokimyasal olarak kobaltla kaplanmasıyla süperkapasitörler için alternatif bir elektrot malzemesi elde edilebilir.

\section{TEŞEKKÜR}

Perihan Yılmaz Erdoğan ve Naime Özdemir doktora bursu için YÖK 100-2000 programına teşekkür ederler. Yazarlar, Gaziantep Üniversitesi BAP birimine FEF.DT.19.40 kodlu proje desteği için teşekkür ederler.

\section{KAYNAKLAR}

[1] S. R. Sharvini, Z. Z. Noor, C. S. Chong, L. C. Stringer, and R. O. Yusuf, "Energy consumption trends and their linkages with renewable energy policies in East and Southeast Asian countries: Challenges and opportunities," Sustain. Environ. Res., vol. 28, no. 6, pp. 257-266, 2018.

[2] S. Najib and E. Erdem, "Current progress achieved in novel materials for supercapacitor electrodes: mini review," Nanoscale Adv., vol. 1, no. 8, pp. 2817-2827, 2019.

[3] A. Noori, M. F. El-Kady, M. S. Rahmanifar, R. B. Kaner, and M. F. Mousavi, "Towards establishing standard performance metrics for batteries, supercapacitors and beyond," Chem. Soc. Rev., vol. 48, no. 5, pp. 1272-1341, 2019.

[4] L. H. Saw et al., "Numerical modeling of hybrid supercapacitor battery energy storage system for electric vehicles," Energy Procedia, vol. 158, pp. 2750-2755, 2019.

[5] Y. Chai, Z. Li, J. Wang, Z. Mo, and S. Yang, "Construction of hierarchical holey graphene/MnO2 composites as potential electrode materials for supercapacitors," J. Alloys Compd., vol. 775, pp. 1206$1212,2019$.

[6] Xian Jian et al., "Carbon-Based Electrode Materials for Supercapacitor: Progress, Challenges and 
Prospective Solutions,” J. Electr. Eng., vol. 4, no. 2, pp. 75-87, 2016.

[7] K. Wang, H. Wu, Y. Meng, and Z. Wei, "Conducting polymer nanowire arrays for high performance supercapacitors,” Small, vol. 10, no. 1, pp. 14-31, 2014.

[8] R. S. Kate, S. A. Khalate, and R. J. Deokate, "Overview of nanostructured metal oxides and pure nickel oxide ( $\mathrm{NiO}$ ) electrodes for supercapacitors : A review,” J. Alloys Compd., vol. 734, pp. 89-111, 2018.

[9] Y. Li et al., "Ni-Co sulfide nanowires on nickel foam with ultrahigh capacitance for asymmetric supercapacitors," J. Mater. Chem. A, vol. 2, no. 18, pp. 6540-6548, 2014.

[10] Y. Sui, Y. Zhang, H. Hu, Q. Xu, F. Yang, and Z. Li, "High energy density asymmetric supercapacitor based $\mathrm{ZnS} / \mathrm{NiCo} 2 \mathrm{~S} 4 / \mathrm{Co} 9 \mathrm{~S} 8$ nanotube composites materials," Adv. Mater. Interfaces, vol. 5, no. 12, p. 1800018, 2018.

[11] Jayalakshmi, M., \& Balasubramanian, K. (2008). Simple capacitors to supercapacitors-an overview. Int. J. Electrochem. Sci, vol. 3, no. 11, pp. 1196-1217, 2008..

[12] X. Wang, A. Sumboja, M. Lin, J. Yan, and P. S. Lee, "Enhancing electrochemical reaction sites in nickelcobalt layered double hydroxides on zinc tin oxide nanowires: a hybrid material for an asymmetric supercapacitor device," Nanoscale, vol. 4, no. 22, pp. 7266-7272, 2012.

[13] I. Shakir, M. Shahid, U. A. Rana, I. M. Al Nashef, and R. Hussain, "Nickel-Cobalt layered double hydroxide anchored zinc oxide nanowires grown on carbon fiber cloth for high-performance flexible pseudocapacitive energy storage devices," Electrochim. Acta, vol. 129, pp. 28-32, 2014.

[14] D. Yang and M. I. Ionescu, Metal Oxide-Carbon Hybrid Materials for Application in Supercapacitors, in Metal Oxides in Supercapacitors. Elsevier, pp. 193-218. 2017.

[15] Z. Xun, C. Cai, W. Xing, and T. Lu, "Electrocatalytic oxidation of dopamine at a cobalt hexacyanoferrate modified glassy carbon electrode prepared by a new method," J. Electroanal. Chem., vol. 545, pp. 19-27, 2003.

[16] V. Gupta, S. Gupta, and N. Miura, "Potentiostatically deposited nanostructured CoxNi1- x layered double hydroxides as electrode materials for redox-supercapacitors," J. Power Sources, vol. 175, no. 1, pp. 680$685,2008$.

[17] C. Zhao and W. Zheng, "A review for aqueous electrochemical supercapacitors," Front. Energy Res., vol. 3, p. 23, 2015.

[18] C. Lupi, A. Dell'Era, and M. Pasquali, "Nickel-cobalt electrodeposited alloys for hydrogen evolution in alkaline media,” Int. J. Hydrogen Energy, vol. 34, no. 5, pp. 2101-2106, 2009.

[19] Q. Li, J. Chen, L. Fan, X. Kong, and Y. Lu, "Progress in electrolytes for rechargeable Li-based batteries and beyond," Green Energy Environ., vol. 1, no. 1, pp. 18-42, 2016.

[20] G. Wang, L. Zhang, and J. Zhang, "A review of electrode materials for electrochemical supercapacitors," Chem. Soc. Rev., vol. 41, no. 2, pp. 797-828, 2012.

[21] Q. Hu et al., "Intracellular polymer substances induced conductive polyaniline for improved methane production from anaerobic wastewater treatment," ACS Sustain. Chem. Eng., vol. 7, no. 6, pp. 5912-5920, 2019.

[22] T. M. Masikhwa, M. J. Madito, D. Momodu, A. Bello, J. K. Dangbegnon, and N. Manyala, "High electrochemical performance of hybrid cobalt oxyhydroxide/nickel foam graphene," J. Colloid Interface Sci., vol. 484, pp. 77-85, 2016. 
[23] S. R. Majid, "Green synthesis of in situ electrodeposited rGO/MnO 2 nanocomposite for high energy density supercapacitors," Sci. Rep., vol. 5, p. 16195, 2015.

[24] S. H. Kim, Y. Il Kim, J. H. Park, and J. M. Ko, "Cobalt-manganese oxide/carbon-nanofiber composite electrodes for supercapacitors," Int. J. Electrochem. Sci, vol. 4, pp. 1489-1496, 2009.

[25] Q. Mahmood et al., "Transition from Diffusion- Controlled Intercalation into Extrinsically Pseudocapacitive Charge Storage of MoS2 by Nanoscale Heterostructuring," Adv. Energy Mater., vol. 6, no. 1, p. 1501115, 2016.

[26] L. Zhu, W. Wu, Y. Zhu, W. Tang, and Y. Wu, "Composite of CoOOH nanoplates with multiwalled carbon nanotubes as superior cathode material for supercapacitors," J. Phys. Chem. C, vol. 119, no. 13, pp. 7069$7075,2015$.

[27] C. J. Raj et al., "Rapid hydrothermal synthesis of cobalt oxyhydroxide nanorods for supercapacitor applications," J. Electroanal. Chem., vol. 747, pp. 130-135, 2015.

[28] B. Sarma, R. S. Ray, S. K. Mohanty, and M. Misra, "Synergistic enhancement in the capacitance of nickel and cobalt based mixed oxide supercapacitor prepared by electrodeposition," Appl. Surf. Sci., vol. 300, pp. 29-36, 2014.

[29] A. Yavuz, M. Y. Haciibrahimoğlu, and M. Bedir, "Synthesis and characterisation of Co-Co(OH)2 composite anode material on $\mathrm{Cu}$ current collector for energy storage devices," Mater. Res. Express, vol. 4, no. 4, 2017.

[30] A. Yavuz, P. Y. Erdogan, N. Ozdemir, H. Zengin, G. Zengin, and M. Bedir, "Electrochemical synthesis of $\mathrm{CoOOH}-\mathrm{Co}(\mathrm{OH}) 2$ composite electrode on graphite current collector for supercapacitor applications," $J$. Mater. Sci. Mater. Electron., vol. 30, no. 20, pp. 18413-18423, 2019. 